\title{
Fındık ıslahında gelişmeler
}

\author{
Ali İSLAM 1 \\ ${ }^{1}$ Ordu Üniversitesi, Ziraat Fakültesi, Bahçe Bitkileri Bölümü, Ordu
}

Alınış tarihi: 30 Kasım 2019, Kabul tarihi: 30 Aralık 2019

Sorumlu yazar: Ali İSLAM, e-posta: islamali@hotmail.com

\section{Öz}

Dünya findık üretimi son yılların ortalamalarına göre yaklaşık olarak 900 bin ton olup bu üretim sürekli artış eğilimindedir. En önemli fındık çeşitleri doğal yetişme alanlarındaki geniş bir popülasyon içerisinden üretici gözlemlerine dayalı seleksiyonlarla ortaya çıkarılmıştır. Buna en güzel örnek üstün kalitesi ile 'Tombul' çeşidi verilebilir. Fındık ıslahında dikkate alınan temel özellikler meyve ve verim özellikleri, morfolojik ve fenolojik özellikler, dayanıklılı ve anaç üzerine yoğunlaşmaktadır. Türkiye ve İtalya en büyük üretici ülke olmasına rağmen son yıllarda findık ıslahı konusunda en geniş çalışmalar ABD'de yürütülmektedir. Son yıllarda moleküler marker tekniklerine dayalı çalışmalar üzerine yoğunlaşılmış ve önemli ilerlemeler kaydedilmiştir. EFB ye dayanıklı yeni çeşit olarak 'Gasaway' geliștirilmiş ve sonraki çalışmalarda bu dayanıklılık genleri kullanılmıştır. 'Okay28', 'Giresun Melezi', 'Allahverdi', 'Jefferson', Webster', 'Yamhill', 'PollyO' son yillarda geliştirilen yeni çeşitlere örnek olarak verilebilir. Çeşit ve anaç ıslahı uzun süreli ve sabır isteyen bir iştir. Çok yönlü, kapsamlı ve sürdürülebilir olan çalışmalara ihtiyaç duyulur. Farklı ekolojiler için yüksek verimli, kaliteli, biotik ve abiyotik koşullara dayanıklı çeşitler elde etmek esastır. Farklı tüketim alışkanlıklarına uygun çeşitlerin de geliştirilmesi arzulanmaktadır. Ayrıca rekreasyonel açıdan da peyzaj tasarımlarında findık ıslahı önem taşımaktadır.

Anahtar kelimeler: Corylus, findık, seleksiyon, melezleme, çeşit, anaç, peyzaj

\section{Advances in hazelnut breeding}

\section{Abstract}

World hazelnut production is about 900 thousand tons and this production tends to increase continuously. The most important hazelnut varieties were obtained by selection based on producer observations which took many years among the hazelnut plantations that grown in nature. The best example is 'Tombul' variety, which considered to be very superior in quality. The main features for hazelnut breeding are indicated on nut and yield characteristics, vegetative (morphological and phenological) characteristics, resistance to major pests and diseases, and rootstock breeding. In recent years, the most studies have been carried out on hazelnut breeding in the USA. And it has been continued in some other countries such as Turkey, Spain, Italy, China, etc. In recent years, hazelnut breeding studies have been focused on molecular marker techniques and significant progress has been made. A new EFB-resistant type 'Gasaway' was developed and resistance genes have been used in subsequent studies. Some new varieties are 'Okay28', 'Giresun Melezi', 'Allahverdi', 'Jefferson', Webster', 'Yamhill', 'PollyO'. The variety and rootstock breeding in hazelnuts require long time and patience. Long-term projects should be maintained in a multi-faceted manner. It is desirable to obtain varieties suitable for different ecologies, high yield, quality, resistant to biotic and abiotic conditions. In addition, it can be improved hazelnut varieties suited to different consumption habits. Hazelnut breeding is also important for recreational purposes.

Key words: Corylus, hazelnut, selection, crossing, cultivar, rootstock, landscape 


\section{Giriş}

Fındık dünyanın kuzey yarımküresinde 42-45 enlem derecelerinde yer alan ılıman iklim kuşağında geniş bir alanda yayılmıştır. Genellikle sahil bölgelerde ve ılıman iklimde iyi yetişir. Buna en iyi örnek Türkiye'nin Karadeniz kıyı şeridi verilebilir (İslam, 2018). Yine İspanya ve İtalya'da kıyı bölgelerde fındık tarımı yaygındır. ABD de ise findık Pasifikten etkilenen Williamette vadisinde iyi yetişmektedir. Kafkaslar ve Balkanlar da önemli üretim alanı olmakla beraber Çin ve Hindistan gibi farklı ekolojilerde de fındık türleri yetișmektedir. Diğer yandan son 20 yılda Şili gibi güney yarımkürede de yetiştiricilik artmaktadır.

Fındık yetiştiriciliğinin tarihi Akdeniz bölgesinde klasik peryoda kadar gider. Kafkaslar ve Türkiye'de ise daha önceki zamanlardadır. Son yapılan araştırmalarda findık ticaretine ait en eski bulgulara orta bronz çağında (MÖ 2000-1700) Kayseri Kültepe'de rastlanmıştır (Fairbairn ve ark. 2014). 0 halde eski çağlardan itibaren findık insanoğlunun önemli bir gıdası olarak devam etmektedir. Dünya fındık üretimi yaklașık 900 bin tondur (FAO, 2017). Türkiye lider üretici ülke olup dünya üretiminin yaklaşık \%70'ini oluşturmaktadır. İtalya \%22 ile ikinci sırada yer almaktadır. Fındık meyvesi, gıdalarda, kozmetik ve ilaç sanayinde yaygın kullanılmaktadır.

Findık (Corylus L.) Betulaceae familyasına aittir. Corylus cinsi içerisinde 9-25 kadar tür bulunmaktadır. Bazı türler çalı, bazı türler ağaç formundadır. Yüksek çalı olarak bilinen bazı türler Corylus avellana L., C. americana Marshall, C. cornuta Marshall, $C$. heterophylla Fischer ve $C$. sieboldiana Blume dır. Ağaç formlu olan findıklara C. colurna $\mathrm{L}, C$. jacquemontii Decaisne, C. chinensis Franchet, $C$. ferox Wallich örnek olarak verilebilir.

Kuzey yarımkürede 11 Corylus türü yaygın olarak bulunur. Asya ve Avrupa'da 2 tür (C. avellana ve $C$. colurna), Kuzey Amerikada 3 tür (C. americana, $C$. cornuta ve $C$. californica), Himalayalarda 1 tür $(C$. jacquemontii). Diğerleri doğu Asya kökenli olup 3 ağaç türü $C$. chinensis, $C$. fargesii Schneid. ve $C$. ferox, ve 2 çalı türü (C. heterophylla ve $C$. sieboldiana) yer almaktadır (Whitcher ve Wen, 2001).

Pekçok taksonomist tür içerisinde geniş bir polimorfizm olduğundan bahsetmektedir (Mehlenbacher ve Smith, 1991; Thompson ve ark., 1996; Gökirmak ve ark., 2009). SSR markerleri kullanılarak yapılan biyoçeşitlilik çalışmalarında jeografik orjine göre 4 gruptan bahsedilmektedir.
Bunlar Karadeniz, İspanya-İtalya, Orta Avrupa ve İngiltere bölgesine aittir (Boccacci ve ark., 2006; Gökirmak ve ark., 2009). Corylus türlerinde diploid kromozom sayısı $2 \mathrm{n}=22$ iken, $\mathrm{x}=12$ veya triploid türlerin varlığı da bilinir. Corylus türlerinden tetraploid türler de elde edilmiştir (DanielssonSantesson, 1951; Kasapligil, 1968; Salesses, 1973; Botta ve ark., 1997).

C. avellana bitkileri, 3-7 m boylanan, geniş yaprakll, yüksek çalı formlu, çok sayıda dip sürgünü verme eğiliminde olan bir türdür. Ticari türlerin hemen hemen tamamı Türkiye ve Avrupa'da bulunan $C$. avellana popülasyonlarından seçilmiștir. Yüksek kaliteli çeşitler modern ıslah programlarının temelini oluşturmuştur. $\mathrm{Bu}$ çeşitler ıslah programlarında tek başına kullanıldığı gibi diğer çeşitler veya türlerle beraber de kombine edilmektedir. Bu çalışmada fındık bitkisinin yapısı, çiçeklenme biyolojisi, ıslahın amaçları, son yıllarda fındık ıslahı konusunda yapılan araştırmalar ile geliştirilen çeşitler üzerine odaklanılmıştır.

\section{Çiçeklenme biyolojisi}

Findıklar monoik, dikogam, anemofil ve kendine uyuşmaz olarak bilinir. Erkek çiçeklerin herbiri silindirik yapıda, 150-200 çiçek içeren salkım (püs, kedicik) yapıdadır. Salkımlar 4-10 kadar kedicik içerir ve 4-40 milyon polen yayar. Polen canllı̆̆g çeşitlere göre değişir. Bazı çeşitlerde \%30-50 oranında cansızdır. Dişi çiçekler (karanfil) yaklaşık 2-12 dişi organ içerir. Stigma iki ay kadar reseptiv kalabilir. Ancak çiçeklenmeden itibaren ilk 15 günlük süre polen çimlenmesi için daha kabul edilebilir görülmektedir. Tozlanmadan sonra polen stigma yüzeyinde çimlenir, 4-10 gün içerisinde stil içerisine girişi tamamlanır. Stil tabanına ulaştığında polen tübü genişler ve ince bir kallüs tabakası ile örtülür. Ovaryum dokusu gelişene kadar bekler. Tozlanma ve çiçek tozu çim borusu gelişimi ovul gelişimini teşvik eder (Germain, 1994; Beyhan, 2000; Liu ve ark, 2014).

Tozlaşma tamamlandıktan sonra, stigma turgoru kaybederek kararır. Tozlaşmayan stigma, biraz daha fazla genişler ve daha uzun süre reseptiv kalabilir (3 aya kadar) (Beyhan, 1993). Çeşitlerin yaklaşık \% 90'ı protandridir (Olsen ve ark, 2000). Fındık çeşitlerinde dikogami vardır ve protandri yaygındır (Beyhan, 2000). Bu durum, ekolojik koşullara göre de değişebilir (Crepinsek ve ark, 2012). Örneğin, Oltenia bölgesinde, çoğu fındık çeşidi protogini davranış sergiler. Dikogami tipi olarak bu değişiklik "Hall's 
Giant", "Romavel" ve "Du Chilly " için de gözlemlenmiştir (Botu ve ark, 2017).

Fındık monoik bir çiçek yapısına sahiptir ve kış aylarında rüzgârlı koşullarda tozlaşır. Tomurcuklardaki dişi çiçeklerin sayısı çeşitlere göre değişir. Örneğin, Kalınkara çeşidinde 34 kadardır. Genel olarak, tomurcuklarda daha fazla dişi çiçek olan çeşitler daha verimli tozlanma gerçekleştirir. Erkek ve dişi çiçeklerin açış zamanı ve süreleri, çeşit, yaş ve ekolojik koşullara göre değişir (Beyhan, 2000).

Corylus heterophylla L. türünde erkek çiçeklerin yaklaşık \%50-67'si abortivdir (Liu ve ark, 2014). Neredeyse tüm findık çeşitleri kendine uyuşmazdır ve birçok çeşitler karşılıklı uyuşur. Fındıklardaki uyuşmazlık S-allel ile tek bir lokus tarafından kontrol edilen sporofitik tiptir. Allel genler erkek çiçeklerde dominanttır (Mehlenbacher ve Thompson, 1988). Erdoğan ve Mehlenbacher (2000) tarafından yapılan bir melezleme çalışması, salkım sayısının genotiplere göre değiştiğini göstermiştir. Avrupa findıkları, $C$. avellana, C. colurna ile iyi uyum gösterirken, Kuzey Amerikan türleri ise $C$. cornuta ve $C$. californica yüksek oranda karşılıklı uyuma sahiptir. Bu durumu Erdoğan ve Mehlenbacher (2001) yabani Corylus türlerinde uyuşmazlık çalışmaları ile rapor etmişlerdir.

Yabani Corylus türleri, mevcut findık çeşitlerinin iyileştirilmesi için ıslah araştırmalarında önemli bir rol oynamaktadır (Thompson ve ark, 1996). Mehlenbacher ve Smith (1991) tarafindan 1988 ve 1990 yıllarında Corylus avellana L. çeşitlerinin kendi kendine tozlaşması çalışmasında, 'Tombul' ve 'Montebello'da kısmi uyuşmazlığın varlığını ortaya koymuştur. $\mathrm{Bu}$ çeşitlerde belirlenen meyve tutumunun ortalaması sirasıly $\% \quad 44 \quad$ ve\% $\quad 20$ arasındadır. Mehlenbacher ve Smith (1991), S30'un stil kısmı mutasyonu gibi görünen yeni bir S-alleli (S28) bildirmişlerdir. Bunun yanında, doğal çevrenin yarattığı adaptasyona bağlı olarak $C$. heterophylla ve C. mandshurica'nın kendine uyuşur olduğu bildirilmiştir (Zhai ve ark, 2009). Fındık tür ve çeşitlerinin uyuşma durumları üzerine daha fazla çalışmalar yapılmalıdır.

Polen tüplerini kısa, genellikle virgül şeklinde, belirgin sonlanan olarak tanımlayan Erdoğan ve Mehlenbacher (2001), bazı kendine ve karşılıklı tozlaşmalarda hem uyumlu hem de uyumsuz reaksiyonlar gözlemişlerdir. Kontrollü kendi kendine tozlașmanın ise, $C$. americana ve $C$. sieboldiana türlerinde düşük tutum ile sonuçlandığını, dört $C$. californica'dan birinin ve üç $C$. colurna seçiminden ikisinin iyi tutum sağladığını belirlemişlerdir. Benzer çalışmalar Erdoğan ve ark (2005); Ma ve ark., (2013); Xie ve Liu (2014); Korkmaz ve ark., (2015); ve Hosseinpour ve ark (2015) tarafından da yürütülmüștür.

\section{Fındık ıslahının amaçları}

Fındıkta başlıca ıslah amaçları büyüme gücü, verim ve meyve kalitesi, biyotik/abiyotik koşullara dayanıklılık, anaç seçimi ve iyi afinite olarak siralanabilir.

Fındık çeşitlerinde verim ve kalite üzerine dikim ve terbiye sistemleri, budama, gübreleme, sulama, hastalık ve zararlılarla mücadele gibi faktörler etki etmekle birlikte (İslam ve ark, 2005) en önemli faktör çeşit genetik yapısıdır. Yetiştiriciliği yapılan çeşitler büyüklük, şekil, iç oranı, kabuk kalınlığı gibi özellikler yönünden birbirinden farklılık göstermektedir. Çeşit ıslahı için yüksek verim ve yüksek kalite özellikleri aranır. Önemli meyve karakterleri olarak yüksek oranda dolgun iç, yüksek randıman, tam beyazlama, ince kabukluluk, üniform iç büyüklüğü ve şekli, düşük iç meyve kusurları (buruşuk iç, eksik iç, küflü meyve, çift iç vs) istenmektedir. Vejetatif özellikler olarak dip sürgünü oluşturmama veya az oluşturma, iyi aşı uyuşması, mekanik hasat için dik büyüme, ilkbahar donlarından sakınmak için geç uyanma sayılabilir (Thompson ve ark., 1996; Mehlenbacher, 2003; Islam, 2000 ve 2003).

Islah için arzu edilen diğer özellikler ise biyotik ve abiyotik koşullara dayanıklılıktır. Fındık ıslahı için dayanıklılık istenen önemli zararlılar şunlardır: tomurcuk akarl, Phytoptus avellanae Nal. (hemen hemen fındık yetiştirilen tüm bölgelerde yaygındır), findlk kurdu, Curculio nucum L. (Avrupa ve Asya'da), kabuklu bitler, ambrosia (Xyleborus spp) (daha ziyade Türkiye'de) ve Haliomorpha halys (Avrupa ve diğer ülkelerde). Fındık ıslahında hastalıklara karşı dayanıklılık da istenir. Bunlar Doğu findık yanıklığı (EFB) (Anisogramma anomala (Peck) E. Muller, Kuzey Amerika'da), bakteriyel yanıklık (Xanthomonas campestris pv. Corylina, ABD ve batı Avrupa'da yaygın), Gloeosporium coryli (Desm.) Sacc. (syn. Monostichella coryli (Desm.) Hohnel) (Avrupa ve Asya) ve külleme (Erysiphe corylacearum, Türkiye ve İran). Diğer yandan düşük sıcaklıklar, kuraklık, tuz stresi, vs diğer abiyotik faktörlerdir.

Anaç ıslahı için dip sürgünü oluşturmama ve dik büyüme iki önemli anahtar özelliktir. 
Park ve bahçelerde rekreasyonel olarak kullanılan fındık bitkisinde yeşil-sarı-kırmızıya kadar değişen yaprak ve çotanak renkleri istenir. Amaca göre farklı büyüme gücü ve habitüsü arzulanır. Yine süs bitkisi açısından kış dönemi bol erkek çiçek varlığı da istenen diğer bir husustur.

\section{Fındık ıslahındaki gelişmeler}

\section{Çeşit ıslahı}

Fındık için yaygın kullanılan geleneksel ıslah yöntemleri seleksiyon ve melezlemedir. Türkiye'de melezleme yolu ile ıslah programı Okay tarafından 1981'te başlatılmış olup yüksek verimli ve ince kabuklu "Tombul" ile büyük meyveli "Kargalak" çeşitleri melezlemeye tabi tutularak bu çeşitlerin üstün özelliklerinin birleștirilmesi amaçlanmıştır. İlk seçimden elde edilen 44 birey ile iki aşamalı seleksiyon yapılmıştır (Okay, 1999). 2012 yılında elde edilen tiplerden ikisi ümitvar görülerek 'Giresun Melezi' ve "Okay 28" olarak tescillenmiștir (Balık ve ark, 2015; İslam, 2018).

Seleksiyon ıslahı, Türkiye'de en çok kullanılan ıslah yöntemidir. Klonal seleksiyon yöntemi bir çok çeşit için kullanılmıştır: 'Tombul' çeşidinde (İslam, 2000; Demir ve Beyhan, 2000; Turan, 2007; Balık ve ark, 2014); 'Uzunmusa' çeşidinde (İslam, 2003); 'Palaz' ve 'Kalınkara' çeşitlerinde (İslam ve Özgüven, 2001; Demir ve Beyhan, 2000); 'Çakıldak' çeşidinde (Çayan, 2019) pek çok çalışma yürütülmüştür. Bir çeşidin klonları arasındaki genetik varyasyon miktarı, bir bütün olarak C. avellana türü içerisinde olandan çok daha az olduğu için, klonal seçim genetik iyileşme için geleneksel bir yaklaşım olarak düşünülebilir. Türk findık çeşitlerinin klonlar topluluğu olduğu da ifade edilmektedir (İslam, 2003, Mehlenbacher, 2018a).

İtalya'daki klon seleksiyonu programları 'Tonda di Giffoni' (Petriccione ve ark, 2010); 'Tonda Gentile delle Langhe' (Marinoni ve ark, 2000; Valentini ve ark, 2001, 2014); ve 'Tonda Gentile Romana' (Monastra ve ark, 1996) çeşitleri üzerindedir. İspanya'da 'Gironel' ve 'Negret' çeşitlerinde (Rovira ve ark, 1996) klonal seleksiyon uygulanmıştır. Farinelli ve ark., tarafindan (2009) 'Tonda Gentile Romana ile 'Tonda di Giffoni' melezlenmiş ve ardından seleksiyon yapmıştır. F25P29 ve F13P9 melezleri oldukça iyi bir iç oranına (yaklaşık \% 51) sahip bulunmuștur. Diğer melezler (F4P32, F25P29 ve F13P9), iyi iç kalitesi ve yüksek randıman göstermiştir. Ancak verimlerinin kültürel teknikler veya daha fazla ıslah çalışmaları ile iyileștirilmesi gerektiği vurgulanmıştır. Araştırmalar sonucunda bazı yeni İtalyan çeşitleri ('Madonella', 'Romanella', 'Tonda Etrucsa' ve 'Tonda Francescana') kısa bir süre önce tanıtılmıştır (Mehlenbacher, 2018a).

Corylus avellana'nın (Avrupa fındı̆̆ı) soğuğa duyarlı olduğu bilinmektedir. Genç sürgünler (erken tomurcuk patlaması) ilkbaharda dona maruz kalmaktadır. Buna karşılık C. heterophylla (Siberian hazelnut) oldukça dayanıklıdır. Çin'de soğuklara dayanıklılık, yüksek verim ve meyve kalitesi öne alınarak türler arası hibridizasyon yapılmış, dişi ebeveyn olarak $C$. heterophylla ile erkek ebeveyn olarak C. avellana kullanılmıştır. Ortaya çıkan hibrit türler "Ping'ou" olarak isimlendirilmiştir ("Pingzhen" $\times$ "Ouzhen"). Elde edilen bireylerin iri meyveli, yüksek verimli ve soğuklara daha dayanıklı olduğu ifade edilmektedir. Yapılan değerlendirmeler sonucunda on dört 'Ping'ou' melez çeşidi ortaya çıkmıştır (Wang ve ark, 2018).

Daha önce belirtildiği gibi, mevcut fındık çeșitlerinin ıslah araștırmalarında farklı Corylus türleri, belirli karakterleri bir araya getirme ihtiyacı dolayısı ile önemli bir rol oynamaktadır. Bu hususun, 1970'lerde Romanya'da Vâlcea'da başlatılan ıslah programında, yabani fındık genetik kaynaklarının tanımlanması ve değerlendirilmesinde fayda sağlayacağı ifade edilmektedir (Botu ve ark, 2015). Son yıllarda söz konusu bölgede yapılan araştırmalarda dokuz yeni findık çeşidi piyasaya sürülmüştür (Botu ve ark, 2017).

Amerika Birleşik Devletleri'nde 20. yüzyılın başlarında türlerarası melezleme çalışmaları başlatılmıștır. İlerleyen zamanlarda fındıkta ciddi hasara neden olan Doğu findık yanıklığı (EFB)'na odaklanılarak fındık ıslahı için önemli bir merkez olmuştur. Teknikler arasında hibridizasyon ve markör bazlı seleksiyon bulunmaktadır (Lunde ve ark, 2000). OSU'de yürütülen temel araştırmalar 1969 yılında başlatılmış olup özellikle sanayiye yönelik yüksek oranda beyazlama ve EFB'ye dayanıklılık içermektedir (Coyne ve ark, 1998, Molnar ve ark. 2005). 'Gasaway' dayanıklı olarak tanımlanmıştır. 'Jefferson', 'Yamhill', 'Dorris', 'Wepster' ve 'McDonald' dayanıklı çeşitler olarak Oregon Eyalet Üniversitesi tarafından ortaya çıkartılmıştır (Mehlenbacher, 2018b). Yine dayanıklı çeşitler Rusya, Ukrayna ve Polonya'da da geliştirilmiştir (Capik ve ark., 2013). İspanya, İtalya ve Türkiye'de önemli hasara neden olan elma mozaik virüsüne (ApMV) direnç kaynakları bulmak için de 
çalışmalar devam etmektedir (Akbaş ve Degirmenci, 2010).

Mikrosatellit markörleri, bitki ıslahında markör destekli seçim (MAS) için faydalıdır. Fındık için birçok mikrosatellit markeri geliştirilmiştir (Bassil ve ark, 2005; Boccacci ve ark, 2006; Gürcan ve ark, 2010). Beltramo ve ark (2016), 'Tonda Gentile delle Langhe' × 'Merveille de Bollwiller' çeşitlerinde dip sürgünü verme durumu, uyanma ve büyüme gücü özelliklerine yönelik olarak MAS kullanmışlardır. 163 bitki mikrosatelit markerler kullanılarak analiz edilmiştir. Fındık genom dizisine dayalı olarak 'Jefferson' geliştirilmiştir (Bhattarai ve Mehlenbacher, 2018). Colburn ve ark., (2017), findık için mikrosatellit markörler geliștirmek için 'Jefferson' çeşidinin transkriptom dizisini analiz etmişlerdir. 109 marker lokusunun çoğunlukla benzer coğrafi kökenlerden kümeleme gösterdiği, $C$. avellana içinde yüksek oranda genetik çeşitlilik bulunduğu, ayrıca belirli genleri tașıyan kromozomal bölgelerin belirlenmesi için MAS'ın gelecek ıslah programları açısından önemli olacağı bildirilmiştir.

\section{Anaç islah}

Anaç kullanımı tüm meyve ağaçlarında olduğu gibi fındık için de önem taşımaktadır. Yetiştiricilikte kullanılan çeşitlerin büyüme gücünü etkilemek, erken yaşta verime yatırmak, üretim maliyetlerini azaltmak için dip sürgünü oluşturmayan anaçlar üzerine aşılanması önerilmektedir. Aynı zamanda anaç kullanımı tarımsal mekanizasyon için zorunlu olmamakla beraber kolaylaştırmaktadır. Anaç ıslahı ile ilgili ilk çalışmalar ABD'de başlatılmıştır. Serbest tozlaşma ile $C$. colurna $\times$ C. avellana melezleri elde edilmiștir. Bunlar arasında 'Newberg' ve 'Dundee' seçilerek tescil edilmiştir (Lagerstedt, 1993). Bu anaçların daha sonraki yıllarda EFB'ye duyarlı olduğu tespit edilmiştir. Bu nedenle EFB' ye dayanıklı yeni anaç çeșitleri aranmaya bașlanmıștır. Daha sonra yapılan çalışmalarda, 'Gasaway' dirençli birey olarak bulunmuştur (Mehlenbacher ve ark, 1991). EFB'ye dirençli tozlayıcılar ve diğer türlerdeki dayanıklılık kaynakları için çok sayıda çalışma yürütülmüş (Coyne ve ark., 1998), melez bireylerin dayanıklılığının tanımlanmasına yönelik türler arası hibridizasyon araștırmaları ile pek çok ayrıntı açığa kavuşturulmuştur (Erdoğan ve Mehlenbacher, 2000). Bu çalışmalardan iki çeşit tescil edilerek tanitılmiştır.

Fındıkta dip sürgünü oluşturmayan anaç geliștirilmesi önemlidir. Araștırmaların birçoğu, dip sürgünü olmayan anaç olarak Corylus colurna'ya odaklanmıștır (Ninić-Todorović ve ark, 2012; Miljković, 2017; İslam, 2018). ' 'Negret' çeşidi üzerinde yapılan klon seleksiyonu ile dip sürgünü oluşturmayan anaç geliştirilmiştir (Rovira ve ark, 2012). Türkiye'de kuzey Anadolu'daki büyük genetik çeşitliliğe sahip popülasyonda Corylus colurna L. içerisinde anaç seçimi çalışmaları başlatılmıştır (İslam, 2018). Salimia ve Hoseinovab (2012), İran'daki iklim koşulları için dip sürgünü olmayan anaç geliştirmek için seleksiyon yapmışlardır. İtalya'da da benzer anaç çalışmaları yapılmıştır (Salvador ve ark, 2009; Farinelli ve ark, 2009).

\section{Yeni fındık çeşitleri}

Türkiye'de yaygın olarak yetiștirilen çeșitler 'Tombul', Çakıldak', 'Foșa', 'Mincane' ve Palaz'dır. İtalya'da 'Tonda Gentile delle Langhe', 'Tonda di Giffoni', 'Tonda Romana'; İspanya'da 'Negret' yaygın kültür çeşitleridir. Son zamanlarda geliştirilmiş bazı yeni çeşitler aşağıda verilmiştir.

- 'Okay 28': Fındık Araştırma Enstitüsü tarafından 1981-1999 yılları arasında yapılan çalıșmalar tamamlanarak 2012 yılında tescil edilmiştir. Meyve ağırlığı 2, 85 g, kabuk kalınlığı 0, 74 mm, randıman \% 54, beyazlama oranı \% 92'dir (Anonim, 2019).

- 'Giresun Melezi': 1981-1999 yılları arasında Fındık Araştırma Enstitüsü tarafından geliştirilmiş ve 2012 yılında tescil edilmiştir. Meyve ağırlığı 2, 39 g, randıman \% 51, beyazlama oranı \% 89'dur (Anonim, 2019).

- 'Allahverdi': Seleksiyon çalışmalarında tesadüf çöğürü olarak bulunmuştur. 'Tombul'a göre tomurcuk patlaması 15 gün geç, daha yüksek verimli ve daha dik büyüme habitüsüne sahiptir (Anonim, 2019).

- 'Yamhill': Oregon Deneme İstasyonunda 2008 yılında piyasaya sürülmüștür. Anisogramma anomala (Peck) E. Müller fungusunun neden olduğu EFB ye dayanıklıdır. Yüksek verimli, erken olgunlaşan, yüksek iç oranı ve dolgun iç oranına sahiptir (Mehlenbacher ve ark, 2009)

- 'Jefferson': 2011 yılında Oregon'da piyasaya sürülmüş yeni bir çeşit. Anisogramma anomala (Peck) mantarının neden olduğu EFB'ye dayanıklı, verimli, büyük meyveli ve dolgun iç oranı yüksek bir çeşittir (Mehlenbacher ve ark., 2011).

- 'Wepster': Ocak 2013'te Oregon Deneme İstasyonu tarafından 'Yamhill' e alternatif olarak beyazlama oranı daha yüksek yeni bir çeşittir. EFB'ye karşı tam dirençli, yüksek verimli, küçük meyveli, erken olgunlaşan, kuvvetli taç yapısına sahiptir. Oregon'un 
Willamette Vadisi ve diğer benzer iklim alanları için 'Wepster' önerilir (Mehlenbacher ve ark, 2014).

- 'PollyO': Bu çeșit sanayiye yönelik olarak beyazlama oranı yüksekliği ile dikkat çekmektedir. Oregon'da 'McDonald' ve 'Wepster' in bir tamamlayıcısı olarak ve 'Yamhill' in alternatifi olarak 2018'de yayınlandı. Anisogramma anomala (Peck) E. Müller'in neden olduğu doğu findık yanıklığına (EFB) karşı yüksek dayanıklılık seviyesi, yüksek verim, küçük-orta irilikte, yüksek randımanlı, erken olgunlaşan, iyi iç kalitesi ve kuvvetli bir ağaç formuna sahiptir. Bu çeşit Oregon'un Willamette Vadisi ve benzer iklime sahip diğer bölgeler için önerilmektedir Mehlenbacher ve ark, 2019).

- 'York' ve 'Felix': Bunlar Corylus avellana için tozlayıcı olarak geliştirilmiştir (Mehlenbacher, 2018a). 'York' orta sezonda, 'Felix' geç mevsimde polen açmaktadır.

- 'Ping'ou ': Bunlar Çin'de melezlemelerden seçilen bireylerdir. Bu bireylerin yüksek verimli, iri meyveli ve soğuğa dayanıklı olduğu ifade edilmektedir (Wang ve ark, 2018).

Yukarıda sayılan çeşitler gelecekteki yetiştirme ve ıslah programları için önemli bir potansiyel olarak görülmektedir.

\section{Fındık ıslahının geleceğine yönelik hedefler}

Dünyada ortalama findık üretimi yaklaşık 900 bin ton olup gelecekteki talebi karşılamak için bunun 1,5 milyon tona yükselmesi beklenmektedir. Üretim alanı ise 2017 yılı FAO verilerine göre 672221 ha'dır. Üretimde yetiştirme alanını genişletmekten ziyade mevcut yetiştirme alanlarındaki verimin artırılmasına ihtiyaç vardır. Bu en iyi şekilde çeşit ıslahı ve yetiştirme tekniklerinin iyileștirilmesi ile elde edilebilir. Islah hedefleri sadece iyileştirilmiş verim ile değil, zararlı ve hastalıklara dayanıklılık, dip sürgünü vermeyen çeşit veya anaçların elde edilmesini de gerektirir. Ağaç formlu dik büyüyen çeşitlerinin geliştirilmesi de önemlidir. Çünkü bu sistemler geniş alanda yoğun entansiv tarıma (dip sürgün kontrolü, yabancı otlar, bitki koruma ve hasat gibi) izin vermektedir. Bununla birlikte, dünyanın birçok yerinde geleneksel yetiştiriciliğe uygun yüksek çalı çeşitlerinin iyileştirilmesi de önemli olacaktır. Çünkü fındık yetiştirilen bazı bölgeler coğrafi veya sosyal açıdan entansiv tarıma yeterince izin vermemektedir. İlave olarak doğal ya da geleneksel yetiştiriciliğin ayrı bir yeri ve pazar değeri de vardır. Diğer bir gereklilik, yeni çeşitlerin ıslah edilmesi için kamu kurumları ve özel sektör arasında daha iyi bir sinerji kurulmalıdır. Ek olarak, sofralık tüketim açısından yada farklı tüketim alışkanlıklarına uygun geliştirilmiş çeşitlere de ihtiyaç duyulacaktır. Ayrıca, fındık bitkisinin süs bitkisi olarak kullanımına yönelik farklı özelliklerinin ortaya konulması ve bu özelliklere göre ıslah çalışmalarının yürütülmesi de önem taşımaktadır.

\section{Kaynaklar}

Akbas, B., Degirmenci, K. 2010. Simultaneous detection of Apple mosaic virus in cultivated hazelnuts by onetube RT-PCR. African Journal of Biotechnology 9(12), 1753-1757.

Anonim, 2019. 'Allahverdi' fındık çeşidi. https://arastirma .tarimorman.gov.tr/findik. Erişim t.: 30/12/2019)

Balık, H. İ., Balık, S. K., Köse, Ç., Duyar, Ö., Sıray, E., Sezer, A., Turan, A., Beyhan, N., Erdoğan, V., İslam, A., Kurt, H., Ak, K., Kalkışım, Ö. 2014. Development of the new cultivars of hazelnut by selection from Tombul hazelnut populations in Giresun and Trabzon Provinces. In: International Mesopotamia Agriculture Congress, Proceeding Books 172-179.

Balık, H. İ., Kayalak Balık, S., Okay, A. N. 2015. Yeni fındık çeşitleri (Okay 28 ve Giresun Melezi). Harran Tarım ve Gıda Bilimleri Dergisi 19(2), 104-109.

Bassil, N. V., Botta, R., Mehlenbacher, S. A. 2005. Microsatellite markers in hazelnut: isolation, characterization, and cross-species amplification. Journal of the American Society for Horticultural Science 130(4), 543-549.

Beltramo, C., Valentini, N., Portis, E., Torello Marinoni, D., Boccacci, P., Sandoval Prando, M. A., Botta, R. 2016. Genetic mapping and QTL analysis in European Hazelnut. Molecular Breeding 36(3), 27.

Beyhan, N. 1993. Bazı önemli fındık çeșitlerinin çiçek gelişim safhaları ve çiçek biyolojileri üzerinde bir araştırma. Doktora tezi. Ondokuzmayıs Universitesi, Fen Bilimleri Enstitüsü, Samsun, 175p

Beyhan, N. 2000. Fındığın Döllenme Biyolojisi. OMÜ Üniversitesi Ziraat Fakültesi Dergisi, 15: 116-122

Bhattarai, G., Mehlenbacher, S. A. 2018. Discovery, characterization, and linkage mapping of simple sequence repeat markers in hazelnut. Journal of the American Society for Horticultural Science 143(5), 347-62.

Boccacci, P., Akkak, A., Botta, R. 2006. DNA typing and genetic relations among European hazelnut (Corylus avellana L.) cultivars using microsatellite markers. Genome 49(6), 598-611

Botta, R., Gianotti, C., Me, G. 1997. Kernel quality in hazelnut cultivars and selections analysed for sugars, lipids and fatty acid composition. Acta Hortic 445: 319-26. 
Botu, M., Achim, G., Cosmulescu, S. 2015. Germplasm evaluation, conservation and breeding of nut crops in Romania. In: 1st European Fruit Research Institutes Network Shell Fruit Species Meeting, Abstract Book, 23.

Botu, M., Botu, I., Achim, G., Preda, S., Scutelnicu, A., Giura, S. 2017. Conservation of fruit tree genetic resources and their use in the breeding process. Annals "Valahia" University of Targoviste Agriculture 11(1), 66-69.

Capik, J. M., Muehlbauer, M., Novy, A., Honig, J. A., Molnar, T. J. 2013. Eastern filbert blight-resistant hazelnuts from Russia, Ukraine and Poland. HortScience 48(4), 466- 473.

Çayan, M. 2019. Gürgentepe'de yetiştirilen 'Çakıldak' fındık çeşidinde klon seleksiyonu. Yayınlanmamıș Yüksek Lisans Tezi, Ordu Üniv. Fen Bilimleri Enst. Ordu.

Colburn, B. C., Mehlenbacher, S. A., Sathuvalli, V. R. 2017. Development and mapping of microsatellite markers from transcriptome sequences of European Hazelnut (Corylus avellana L.) and use for germplasm characterization. Molecular Breeding 37(2), 16.

Coyne, C. J., Mehlenbacher, S. A., Smith, D. C. 1998. Sources of resistance to eastern filbert blight in hazelnut. Journal of the American Society for Horticultural Science 123(2), 253-257.

Crepinsek, Z., Stampar, F., Bogataj, L., Solar, A. 2012. The response of Corylus avellana phenology to rising temperature in north eastern Slovenia. International Journal of Biometeorology 56: 681694.

Danielsson-Santesson, B. 1951. Fortsatta Undersökningar av polyploid hassel. (Investigations of polyploid hazels) Sveriges Pom. Fören. Årsskrift 52, 84-94.

Demir, T., Beyhan, N. 2000. Research on the selection of hazelnuts grown in Samsun. Turkish Journal of Agriculture and Forestry 24, 173-183.

Erdoğan, V., Mehlenbacher, S. A. 2000. Interspecific hybridization in Hazelnut (Corylus). Journal of the American Society for Horticultural Science 125(4), 489-497.

Erdoğan, V., Mehlenbacher, S. A. 2001. Incompatibility in wild Corylus species. Acta Horticulturae 556:163169.

Erdoğan, V., Mehlenbacher, S. A., Köksal, A. İ., Kurt, H. 2005. Incompatibility alleles expressed in pollen of Turkish hazelnut cultivars. Turkish Journal of Biology 29, 111-116.

FAO. 2017. Food and Agricultural Organization. www.fao.org. (Erişim tarihi: 30/12/2019)

Fairbairn A, Kulakoğlu F, Atici L. 2014. Archaeobotanical evidence for trade in hazelnut (Corylus sp.) at Middle Bronze Age Kültepe (c. 1950-1830 B.C.),
Kayseri Province, Turkey. Veg His Archaeobot 23(2):167-174

Farinelli, D., Boco, M., Tombesi, A. 2009. Productive and organoleptic evaluation of new hazelnut crosses. Acta Horticulturae 845, 651-656.

Germain, E. 1994. The reproduction of hazelnut: a review. Acta Horticulturea 351:195-209

Gökirmak, T., Mehlenbacher, S. A., Bassil, N. V. 2009. Characterization of European hazelnut (Corylus avellana) cultivars using SSR markers. Genetic Resources and Crop Evolution 56(2), 147-172.

Gürcan, K., Mehlenbacher, S. A., Botta, R., Boccacci, P. 2010. Development, characterization, segregation, and mapping of microsatellite markers for Europeanhazelnut (Corylus avellana L.) from enriched genomic libraries and usefulness in genetic diversity studies. Tree Genetics and Genomes 6(4): 513-531.

Hosseinpour, A., Seifi, E., Javadi, D., Ramezanpour, S. S. 2015. A preliminary study on pollen compatibility of some hazelnut cultivars in Iran. Advances in Horticultural Science 29(1), 13-16.

İslam, A. 2000. Ordu ili Merkez ilçede yetiștirilen fındık çeşitlerinde klon seleksiyonu. Doktora tezi. Çukurova Üniversitesi Fen Bilimleri Enstitüsü, Adana.

Islam, A. 2003. Clonal selection in 'Uzunmusa' hazelnut. Plant Breeding 122(4), 368-371.

İslam, A. 2018. Hazelnut culture in Turkey. Akademik Ziraat Dergisi 7(2), 259-266.

Islam, A., Ozgüven, A. I. 2001. Clonal selection in the Turkish hazelnut cultivars grown in Ordu Province. Acta Horticulturae 556, 203-208.

Islam, A., Turan, A., Kurt, H. 2005. Effect of Ocak and single trunk training systems on yield and nut quality. Acta Horticulturae 686, 259-262.

Kasapligil, B. 1968. Chromosome studies in the genus Corylus. Sci. Rept. Faculty Sci. Ege University. İzmir. No. 59.

Korkmaz, Ș., Ak, B. E., Sakar, E., Turanoğlu, İ., Söylemez, S. 2015. Meyve ağaçlarında uyuşmazlık mekanizması. Harran Gıda ve Tarım Bilimleri Dergisi 19(3), 180186

Lagerstedt, H. 1993. The evolution of a clonal filbert rootstock. Proceedings of the Nut Growers Association of Oregon, Washington and British Columbia 78, 89-101.

Liu, J., Zhang, H., Cheng, Y., Wang, J., Zhao, Y., Geng, W. 2014. Comparison of ultrastructure, pollen tube growth pattern and starch contain in developing abortive ovaries during the progamic phase in hazel. Frontiers in Plant Science 5, 528. 
Lunde, C. F., Mehlenbacher, S. A., Smith, D. C. 2000. Survey of hazelnut cultivars for response to eastern filbert blight inoculation. HortScience 35, 729-731.

Ma, Q., Wang, G., Liang, W., Chen, X., Liang, L., Zhao, T. 2013. Progress on pollenstigma compatibility in Corylus (hazelnuts): a review. Journal of Forestry Research 24(3), 397-402.

Marinoni, D., Me, G., Valentini, N. 2000. Evaluation of 'Tonda Gentile Delle Langhe' clones. Acta Horticulturae 556: 209-218.

Mehlenbacher, S. A. 2003. Progress and prospects in nut breeding. Acta Horticulturae 622(622), 57-79.

Mehlenbacher, S. A. 2018a. Advances in genetic improvement of hazelnut. Acta Horticulturae 1226, 1-12.

Mehlenbacher, S. A. 2018b. Breeding hazelnuts resistant to eastern filbert blight. Acta Horticulturae 1226, 7378.

Mehlenbacher, S. A., Smith, D. C. 1991. Partial selfcompatibility in 'Tombul' and 'Montebello' hazelnuts. Euphytica 56(3), 231-236.

Mehlenbacher, S. A., Thompson, M. M. 1988. Dominance relationships among $\mathrm{S}$ alleles in Corylus avellana $\mathrm{L}$. Theoretical and Applied Genetics 76, 669-672.

Mehlenbacher, S. A., Thompson, M. M., Cameron, H. R. 1991. Occurrence and inheritance of resistance to eastern filbert blight in 'Gasaway' hazelnut. HortScience 26(4), 410-411.

Mehlenbacher, S. A., Smith, D. C., McCluskey, R. L. 2009. 'Yamhill' hazelnut. HortScience 44(3), 845-847.

Mehlenbacher, S. A., Smith, D. C., McCluskey, R. 2011. 'Jefferson' hazelnut. HortScience 46(4), 662-664.

Mehlenbacher, S. A., Smith, D. C., McCluskey, R. 2014 'Wepster' hazelnut. HortScience 49(3), 346-349.

Mehlenbacher, S. A., Smith, D. C., McCluskey, R.L. 2019. 'PollyO' Hazelnut. HortScience 54(8):1429-1432,

Miljković, I. 2017. Growth and yield of hazelnut varieties on the rootstock Corylus colurna and their own root in ecological conditions of Istria. Pomologia Croatica 21(1-2), 3-12.

Molnar TJ, Goffreda JC, Funk CR. 2005. Developing hazelnuts for the eastern United States. Acta Hortic 68:609-617

Monastra, F., Raparelli, E., Fanigliulo, R. 1996. Clonal selection of 'Tonda Gentile Romana'. 445: 52-56.

Ninić-Todorović, J., Čukanović, J., Kurjakov, A., Mladenović, E., Lazović, R., Todorović, I. 2012. Turkish hazel (Corylus colurna L.) seedling characteristics as rootstock for hazelnut cultivar grafting. Contemporary Agriculture 61(3-4), 240-246.

Okay, A. N. 1999. Melezleme ile findık ıslah projesi. Tarım Bakanlığı, Fındık Araștırma Enstitüsü, Giresun.
Olsen, J. L., Mehlenbacher, S. A., Azarenko, A. N. 2000. Hazelnut pollination. HortTechnology 10: 113-115.

Petriccione, M., Ciarmiello, L. F., Boccacci, P., De Luca, A., Piccirillo, P. 2010. Evaluation of 'Tonda di Giffoni' hazelnut (Corylus avellana L.) clones. Scientia Horticulturae 124(2), 153-158.

Rovira, M., Romero, M., Clave, J. 1996. Clonal selection of 'Gironell' and 'Negret' hazelnut cultivars. In: IV International Symposium on Hazelnut 446: 35-39.

Rovira, M., Cristofori, V., Silvestri, C., Celli, T., Hermoso, J. F., Tous, J., Romero, A. 2012. Last results in the evaluation of 'Negret' hazelnut cultivar grafted on nonsuckering rootstocks in Spain. Acta Horticulturae 1052, 145-150.

Salesses, G. 1973. Cytological study of genus Corylus. A heterozygotic translocation in some low male fertile varieties of hazelnut (C. avellana). Annales de l'amélioration des plantes 23, 59-66.

Salimia, S., Hoseinovab, S. 2012. Selecting hazelnut rootstocks for different climatic conditions of Iran. Crop Breeding Journal 2(2), 139-44.

Salvador, F. R., Lolletti, D., Sabelli, A. 2009. Current progress in the hazelnut breeding program at the fruit tree research Centre-Rome. Acta Horticulturae $845,133-8$

Thompson, M. M., Lagerstedt, H. B., Mehlenbacher, S. A. 1996. Hazelnuts Fruit Breeding, Volume III: Nuts. Janick, J., Moore, J. N. (Eds). John Wiley \& Sons, Inc., New York. ISBN: 0-471-12669-1.

Turan, A. 2007. Bulancak'ta yetiştirilen 'Tombul' findık çeșidinde klon seleksiyonu. Yüksek Lisans Tezi. OMÜ Fen Bilimleri Enst, Samsun.

Valentini, N., Me, G., Vallania, R., Zeppa, G. 2001. New hazelnuts selections for direct consumption. Acta Horticulturae 556, 103-8.

Valentini, N., Calizzano, F., Boccacci, P., Botta, R. 2014. Investigation on clonal variants within the hazelnut (Corylus avellana L.) cultivar 'Tonda Gentile delle Langhe'. Scientia Horticulturae 165, 303-10.

Wang, G. X., Ma, Q. H., Zhao, T. T., Liang, L. S. 2018. Resources and production of hazelnut in China. Acta Horticulturae 1226: 59-64.

Whitcher, I. N., Wen, J. 2001. Phylogeny and biogeography of Corylus (Betulaceae): inference from ITS sequences. Systematic Botany 26, 283-298.

Xie, M., Liu, Z. P. 2014. Studies on pollen viability and pollen-stigma compatibility of hybrid hazelnut. Acta Horticulturae 1052: 117-119.

Zhai, X. J., Dong, F. X., Zhang, R. Q., Wang, G. X., Yi, M. P., Liang, L. S. 2009. Research on the compatibility of five Corylus specie. Journal of Central South University of Forestry and Technology 29(4), 26-30. 